\title{
The role of neurohormonal blockers in the primary prevention of acute-, early-, and late-onset anthracycline-induced cardiotoxicity
}

\author{
Ahmed Ayuna ${ }^{*}$ (D) and Nik Abidin
}

\begin{abstract}
Background: Anthracycline-induced cardiotoxicity has been classified based on its onset into acute, early, and late. It may have a significant burden on the quality and quantity of life of those exposed to this class of medication. Currently, there are several ongoing debates on the role of different measures in the primary prevention of cardiotoxicity in cancer survivors. Our article aims to focus on the role of neurohormonal blockers in the primary prevention of anthracycline-induced cardiotoxicity, whether it is acute, early, or late onset.
\end{abstract}

Main body of the abstract: PubMed and Google Scholar database were searched for the relevant articles; we reviewed and appraised 15 RCTs, and we found that angiotensin-converting enzyme inhibitors (ACEI) and Bblockers were the most commonly used agents. Angiotensin II receptor blockers (ARBs) and mineralocorticoid receptor antagonists (MRAs) were used in a few other trials. The follow-up period was on the range of 1-156 weeks (mode 26 weeks). Left ventricular ejection fraction (LVEF), left ventricular diameters, and diastolic function were assessed by either echocardiogram or occasionally by cardiac magnetic resonance imaging (MRI). The occurrence of myocardial injury was assessed by troponin I. It was obvious that neurohormonal blockers reduced the occurrence of LVEF and myocardial injury in 14/15 RCTs.

Short conclusion: Beta-blockers, especially carvedilol and ACEl, especially enalapril, should be considered for the primary prevention of acute- and early-onset cardiotoxicity. ARB and MRA are suitable alternatives when patients are intolerant to ACE-I and B-blockers. We recommend further studies to explore and establish the role of neurohormonal blockers in the primary prevention of the acute-, early-, and late-onset cardiotoxicity.

Keywords: Anthracycline-induced cardiotoxicity, Primary prevention, Neurohormonal blockers ACEl, Beta-blockers, ARB, MRA

\section{Background}

Anthracycline therapy has an important role in the management of different types of cancer over the last few decades $[1,2]$. Unfortunately, anthracycline-induced cardiotoxicity is one of the recognized side effects; they are, however, still in use due to their high potency in destroying cancer cells [3]. Cardiotoxicity can manifest

* Correspondence: drahmedayuna@gmail.com

Salford Royal NHS Foundation Trust, Manchester, UK differently, including a reduction in LV ejection fraction (LVEF), an increase in LV dimensions, impairment of LV diastolic function, and biochemical, imaging, and cellular markers of myocardial injury. Based on the time of its occurrence, cardiotoxicity can be classified into 3 main groups, acute (immediately after administration of chemotherapy up to 2 weeks), early ( 2 weeks to 1 year), and late ( $>1$ year). The probability of recovery and reversibility is less for the groups with early and late onset, especially more so for the latter group [4]. 
The American Society of Clinical Oncology (ASCO) in 2017 recommended cardioprotective measures for patients with high cardiovascular risk before starting anthracycline therapy. It recommends the use of ACEI, Bblockers, or a combination of both in these patient groups [5]. Similarly, ESC position paper 2016 suggested ACEI, B-blockers, and ARBs as potential cardioprotective measures [6]. ESC and ASCO are in consensus that cardiotoxicity is considered present if LVEF decline > 10\% points from baseline ( $>50 \%$ ) or global LVEF is $<50 \%$.

In this article, we will review the evidence for the role of neurohormonal blockers (ACEI, BB, ARB, and MRA) in the primary prevention of acute, early, and late-onset anthracycline-induced cardiotoxicity (AIC) (Table 1).

\section{Main text}

\section{Methods}

PubMed database and Google Scholar were searched using the following terms: Anthracycline-induced cardiotoxicity, primary prevention of anthracyclineinduced cardiotoxicity, ACEI, ARB, and Beta-blockers. Literature research was carried out from 15 January 2020 to 01 June 2020.

\section{Results}

\section{The role of ACEI}

Based on experimental animal models, researchers have shown that ACEIs provide protection for cardiac function decline due to its inhibition of the reninangiotensin-aldosterone system (RAAS), which plays a crucial role in the development of anthracycline-induced cardiac toxicity $[22,23]$.

Cardinale et al. [24] conducted a randomized controlled, open-labelled trial; 114 cancer patients $(72 \mathrm{fe}-$ males, mean age $45 \pm 12$ years) were enrolled (78\% previous chemotherapy, 5\% hypertensive, $2 \%$ diabetic, and $4 \%$ hypercholesterolemia). All the participants had raised troponin I (TnI) enzyme levels after receiving

Table 1 The evidence for the role of neurohormonal blockers (ACEI, BB, ARB, and MRA) in the primary prevention of acute, early, and late-onset anthracycline-induced cardiotoxicity (AIC)

\begin{tabular}{|c|c|c|c|c|c|}
\hline RCTs & $\begin{array}{l}\text { Sample } \\
\text { size }\end{array}$ & Follow-up period & $\begin{array}{l}\text { Neurohormonal } \\
\text { blocker }\end{array}$ & Parameters assessed & $\begin{array}{l}\text { Outcomes in reducing } \\
\text { cardiotoxicity }\end{array}$ \\
\hline Cardinale et al. [7] & 114 & 12 months & Enalapril & LVEF, LVEDD, LVESD, troponin I & Benefit \\
\hline $\begin{array}{l}\text { OVERCOME trial (Bosch } \\
\text { et al. [8]) }\end{array}$ & 90 & 6 months & $\begin{array}{l}\text { Enalapril, } \\
\text { carvedilol }\end{array}$ & LVEF, LV diastolic function & Benefit \\
\hline $\begin{array}{l}\text { MANTICORE 101- } \\
\text { BREAST study (Pituskin } \\
\text { et al. [9]) }\end{array}$ & 99 & $350 \pm 18$ days & $\begin{array}{l}\text { Perindopril, } \\
\text { bisoprolol }\end{array}$ & LVEF, LVEDVI & $\begin{array}{l}\text { Benefit for LVEF but not } \\
\text { benefit for LVEDVI (both } \\
\text { interventions) }\end{array}$ \\
\hline Gupta et al. [10] & 84 & 6 months & Enalapril & $\begin{array}{l}\text { LVEF, troponin, NTproBNP, } \\
\text { creatine kinase (CK) }\end{array}$ & Benefit \\
\hline Guglin et al. [11] & 468 & 2 years & $\begin{array}{l}\text { Carvedilol, } \\
\text { lisinopril }\end{array}$ & LVEF & Benefit \\
\hline $\begin{array}{l}\text { Georgakopoulos et al. } \\
\text { [12] }\end{array}$ & 147 & $1-3$ years & $\begin{array}{l}\text { Metoprolol, } \\
\text { enalapril }\end{array}$ & LVEF & No benefit \\
\hline Maryam et al. [13] & 91 & 30 days & Carvedilol & $\begin{array}{l}\text { LVEF, diastolic function, } \\
\text { troponin I }\end{array}$ & Benefit \\
\hline $\begin{array}{l}\text { Tashakori Beheshti et al. } \\
{[14]}\end{array}$ & 70 & 1 week & Carvedilol & LVEF, strain, strain rate & Benefit \\
\hline Kalay et al. [15] & 25 & 6 months & Carvedilol & LVEF, diastolic dysfunction & Benefit \\
\hline Abuosa et al. [16] & 154 & 6 months & Carvedilol & LVEF, diastolic dysfunction & Benefit \\
\hline $\begin{array}{l}\text { CECCY trial (Avila et al. } \\
[17])\end{array}$ & 200 & 6 months & Carvedilol & LVEF, troponin I, BNP & Possible benefit \\
\hline Kaya et al. [18] & 45 & 6 months & Nebivolol & LVEF, LVEDD, LVESD, NTproBNP & Benefit \\
\hline $\begin{array}{l}\text { PRADA trial Gulati et al. } \\
\text { [19] }\end{array}$ & 130 & 10-61 weeks & $\begin{array}{l}\text { Candesartan, } \\
\text { metoprolol }\end{array}$ & LVEF, troponin I, BNP & $\begin{array}{l}\text { Benefit Candesartan. } \\
\text { Benefit candesartan + } \\
\text { metoprolol. } \\
\text { No benefit metoprolol. }\end{array}$ \\
\hline Cadeddu et al. [20] & 49 & $\begin{array}{l}\text { One week after each chemo } \\
\text { cycle }\end{array}$ & Telmisartan & $\begin{array}{l}\text { LVEF, strain, and strain rate. } \\
\text { IL-6, reactive oxygen species. }\end{array}$ & Benefit \\
\hline Akpek et al. [21] & 83 & $\begin{array}{l}24.0 \pm 3.9 \text { weeks for } \\
\text { intervention and } 24.3 \pm 2.9 \\
\text { on placebo }\end{array}$ & Spironolactone & $\begin{array}{l}\text { LVEF, LVEDD, LVESD, LV } \\
\text { diastolic function, troponin I, } \\
\text { NTproBNP }\end{array}$ & Benefit \\
\hline
\end{tabular}


anthracyclines. This group of individuals was thought to have a poor prognosis, especially if associated with low LVEF [7, 25]. Participants were randomized to receive either enalapril (5-20 mg per day) or no treatment over 12 months. LVEF was reassessed by transthoracic echocardiogram at baseline and the end of 12 follow-ups [24]. The primary endpoint of the study was the presence of cardiac dysfunction in the form of absolute reduction of LVEF by > 10\% compared with baseline. Forty-three percent of the control group reached the primary endpoint, but none of the enalapril group did $(p<$ 0.001). Additionally, there was an increase in LVEDV and LVESV in the control group only. Thirty-one cardiac events happened during the 12 months of followup. Only one event in the enalapril group occurred in the form of arrhythmia requiring treatment. Cardiac death $(n=2, p=0.49)$, acute pulmonary oedema $(n=4$, $p=0.07)$, HF ( $n=14, p<0.001)$, and arrhythmia requiring treatment $(n=10, p=0.01)$ were seen in the control group [24]. The results were favourable in the use of ACEIs for primary prevention in acute and early cardiac dysfunction in the presence of anthracycline-induced myocardial injury.

In 2018, Gupta and colleagues [10] studied 84 patients with leukaemia and lymphoma (41 and 43 patients, respectively). In contrast to the earlier study, this was a randomized, double-blind, controlled trial. All the patients received doxorubicin/daunorubicin at a cumulative dose of $\geq 200 \mathrm{mg} / \mathrm{m}^{2}$. Those patients were equally randomized to receive either enalapril $(n=44)$ or placebo $(n=40)$ for 6 months. The primary endpoint was a decline of LVEF $\geq 20 \%$ from baseline (> 50\% global LVEF). Troponin I, creatine kinase, and NTproBNP biomarkers were performed at baseline and 6 months later [10]. LVEF reduction was more or less the same in both groups $(62.25 \pm 5.49)$ versus ACEI $(56.15 \pm 4.79)(p<$ $0.001)$. However, a decrease of $\geq 20 \%$ of LVEF was seen in 3 patients in the placebo arm, but none in the ACE-I arm. Interestingly, NTproBNP levels were significantly raised in the placebo group after 6 months (49.60 \pm 35.97) compared with the intervention group (98.60 \pm $54.24)(p<0.001)$, and $\mathrm{cTnI}(0.01 \pm 0.00)$ in placebo vs $(0.011 \pm 0.003)$ in the intervention group $(p=0.0035)$, but not CK $(1.08 \pm 0.18)$ in the former vs $(1.21 \pm 0.44)$ in the latter $(p=0.079)$. Furthermore, none developed heart failure or arrhythmia [10]. Despite the small sample size, the results of this study were consistent with other trials which showed the beneficial role of ACEI in reducing the risk of acute and early cardiotoxicity.

\section{The role of the combination of ACEl and beta-blocker}

OVERCOME trial by Bosch et al. [8] evaluated the combination of enalapril and carvedilol vs placebo in the primary prevention of cardiotoxicity (1:1), $N=90$ (mean age for participants was $50 \pm 13$ years) of patients with haematological malignancies receiving anthracycline therapies. All the patients included had preserved LVEF $(\geq 50 \%)$ at baseline (57\% males, $16 \%$ hypertensive, $11 \%$ hypercholesterolemia, 3\% diabetes mellitus, and 19\% smokers). At least $24 \mathrm{~h}$ before the first cycle of chemotherapy, enalapril and carvedilol were started simultaneously. The maximum dose of enalapril was $5 \mathrm{mg} \mathrm{BD}$ or $10 \mathrm{mg} \mathrm{BD}$, and for carvedilol, it was $25 \mathrm{mg}$ BD. Doses were adjusted according to blood pressure response. Patients were monitored for any signs of heart failure, bradyarrhythmia, hypotension, and significant deterioration in kidney function (creatinine raise $>25 \%$ of baseline reading) [8]. The primary endpoint was a change in LVEF > 10\% from baseline. LVEF was checked for all patients after 6 months by echocardiography as well as cardiac MRI. Patients on enalapril and carvedilol demonstrate a non-significant trend of a lower incidence of LVEF reduction (> 10\% decrease of LVEF from baseline $9.5 \%$ for intervention arm vs $19 \%$ for the placebo, $p$ $=0.22$ ) [8]. Almost all of the participants tolerated the medications very well. In summary, the combination of carvedilol and enalapril may reduce the incidence of LV systolic dysfunction in acute and early AIC.

\section{ACEI vs beta-blockers}

MANTICORE 101-BREAST study by Pituskin et al. [9] is a double-blind, randomized controlled trial, and 99 participants (mean age $52 \pm 10$ ) were randomized to perindopril, bisoprolol, or matching placebo (1:1:1). The primary endpoint was the decline in LVEF $>10 \%$ from baseline and $<50 \%$. All participants received trastuzumab as an adjunctive therapy; however, one-quarter of them received anthracycline.

Cardiac MRI was used to assess LVEF. Patients were observed for $350 \pm 18$ days. Perindopril $2 \mathrm{mg}$, bisoprolol $2.5 \mathrm{mg}$ daily, or one dose of level 1 placebo was given to the patients. Medications were up-titrated to $8 \mathrm{mg}$ perindopril, $10 \mathrm{mg}$ bisoprolol, or level 3 placebo tablets within 3 weeks. The maximum dose was generally welltolerated in the perindopril, bisoprolol, and placebo arms, $75 \%, 65 \%$, and $90 \%$, respectively [9]. Patients who received placebo were a threefold higher risk of developing LVEF decline $(n=1$ perindopril, $n=1$ bisoprolol, $n$ $=6$ placebo; $p=0.03$ ). Interestingly, perindopril or bisoprolol did not reduce or minimize LV remodelling for those patients who had received trastuzumab only or trastuzumab and anthracycline therapy.

A more recent trial included 468 women with nonmetastatic breast cancer (age $51 \pm 10.7$ years) [11]. It was a randomized, multicentre, double-blind, and placebocontrolled trial. The primary endpoint was $>10 \%$ decline of LVEF and LVEF $<50 \%$ as well as treatment interruptions of trastuzumab (treated for 12 months) due to the 
development of cardiotoxicity. The follow-up period was for 2 years. Patients were stratified by anthracycline use and then randomized to take lisinopril, carvedilol, or placebo. Cardiotoxicity events were higher in the placebo group (47\%) compared with $37 \%$ and $31 \%$ in lisinopril and carvedilol groups, respectively. Additionally, cardiotoxicityfree survival was longer on both carvedilol (HR 0.49; $95 \%$ CI $0.27-0.89 ; p=0.009$ ) and lisinopril (HR 0.53; 95\% CI $0.30-0.94 ; p=0.015)$ than on placebo. Patients on active therapy with either ACEI or B-blockers, on both the anthracycline arm and whole cohort, had experienced less interruption in their trastuzumab therapy secondary to cardiotoxicity [11]. This trial approved potential benefits for ACEI and B-blocker on acute, early, and possibly late cardiotoxicity.

Georgakopoulos et al. [12] enrolled 147 patients with lymphoma who were receiving anthracycline chemotherapy. Patients were randomized for three main groups: metoprolol, enalapril, and placebo. Baseline LVEF was $67.7 \%$ for the metoprolol group, $65.2 \%$ for the enalapril group, and $67.6 \%$ for the control group. After 1-3 years of follow-up, the authors reported that HF was less frequent under concomitant treatment than those without treatment ( $n=1$ metoprolol, $n=2$ enalapril, $n=3$ placebo; $X^{2}=1.178 ; p=0.555$ ) [12]. The reasons could be lower cumulative anthracycline dose in this trial, study design, and different types of malignancy.

\section{The role of beta-blockers}

Maryam et al. [13] conducted a single-blind, placebocontrolled study, which enrolled 91 females with breast cancer who were to receive anthracycline chemotherapy. Patients were randomly assigned to carvedilol $(n=46)$ and placebo $(n=45)$. Echocardiogram was performed before and 6 months after the chemotherapy. Both LVEF and diastolic function were assessed. TnI was checked before and 30 days after the initiation of chemotherapy. LVEF was significantly reduced in the placebo group compared with the carvedilol group $(p<0.001)$. Moreover, TnI was significantly higher in the control group compared with the intervention $\operatorname{arm}(p=0.036)$ [13].

Another double-blind, randomized controlled study in 2016 enrolled 70 patients with breast cancers who were candidates to receive doxorubicin. Thirty patients were randomized for carvedilol ( $6.25 \mathrm{mg}$ daily) vs placebo. Interestingly, patients were evaluated 1 week before chemotherapy and 1 week after chemotherapy for LVEF, strain, and strain rate via echocardiogram. There was a significant reduction in all targeted parameters in the placebo group compared with the intervention group ( $p$ $<0.001$ ) [14]. Although the results from this trial were very encouraging, the follow-up was very short and not even enough to monitor for the development of early cardiac toxicity. So this study suggested that carvedilol might be useful in providing primary prevention of acute cardiac toxicity even at a low dose.

One of the earliest trials on carvedilol was a smaller study from 2006 with a sample size of 25 participants. Patients were randomly assigned to either carvedilol or placebo group. Those on the carvedilol arm received $12.5 \mathrm{mg}$ once daily for 6 months. All patients received anthracycline chemotherapy. The mean LVEF in the carvedilol group was almost unchanged at baseline and after the chemotherapy (70.5 vs 69.7 respectively, $p=$ 0.3) [15]. In comparison with the control group, there was a significant reduction in the mean EF, i.e. $>10 \%$ decline from baseline ( 68.9 vs $52.3 ; p<0.001)$. A significant reduction in LV systolic and diastolic diameter and diastolic function was noted on the control group compared with the intervention group. An obvious limitation of this study is the small sample size.

Another interesting trial investigated the role of bblockers in preventing AIC [16]. It was a prospective, randomized, double-blind, controlled study involving 154 patients treated with doxorubicin. Participants were randomized to either carvedilol $6.25 \mathrm{mg} /$ day, $12.5 \mathrm{mg} /$ day, $25 \mathrm{mg} /$ day, or placebo (1:1:1:1). By the end of 6 months of follow-up, only one patient of the 116 who received carvedilol developed an LVEF decline of $>10 \%$ from baseline compared with three from the placebo group. Compared with baseline echocardiogram, there were no significant changes among the 3 different groups of carvedilol (placebo: baseline EF $62.0 \pm 4.6,6$ months $58.2 \pm 6.6, p=0.002 ; 6.25 \mathrm{mg}$ : baseline $61.4 \pm$ 3.9, 6 months $60.0 \pm 2.9, p=0.059 ; 12.5 \mathrm{mg}$ : baseline $60.0 \pm 4.1,6$ months $58.2 \pm 6.6, p=0.100$; 25 mg: baseline $60.4 \pm 4.2,6$ months $59.2 \pm 2.8, p=0.07$ ) [16]. Carvedilol may have had a preventative effect on LVEF as more patients developed LV systolic dysfunction on the placebo arm. However, there were no significant changes in diastolic function, clinical overt heart failure, or death between the two arms of the study.

CECCY trial was a prospective, double-blind, randomized (1:1), placebo-controlled trial [17], $N=200$ (mean age $50.80 \pm 10.10, p=0.14$ ) with breast cancer. All of them were planned to receive doxorubicin with a total cumulative dose of $240 \mathrm{mg} / \mathrm{m}^{2}$. All of them had an LVEF $>50 \%$ before enrolment, and the primary endpoint was to prevent $\geq 10 \%$ reduction of LVEF at 6 months. The secondary outcome was to assess the effect of carvedilol on TnI, BNP, and LV diastolic function. Medications were initiated on the first day of chemotherapy, then uptitrated at 3-week intervals to a maximum dose of $25 \mathrm{mg}$ BD of carvedilol. All the patients had their echocardiogram, TnI, and BNP checked at baseline and a median of 19 days after each cycle of chemotherapy. The primary endpoint was similar in each group, so carvedilol did not result in significant changes in LV function in 6 
months [17]. Nevertheless, TnI significantly raised in the placebo group compared with carvedilol, suggesting that the latter has a protective effect from myocardial injury.

One randomized controlled trial looked at the role of cardioselective B-blocker (nebivolol) in the primary prevention of AIC [18]. It was a prospective, double-blind study with 45 patients who were randomly assigned to receive nebivolol $5 \mathrm{mg}$ daily $(n=27)$ or placebo $(n=18)$. Both echocardiogram and NTproBNP level were checked for all participants at baseline and 6 months of chemotherapy. By the end of 6 months, LVEF, LVEDD, and LVESD were all preserved and unchanged in the nebivolol group (LVESD $30.4 \pm 3.5$ to $31.0 \pm 3.6 \mathrm{~mm}, p$ $=0.20$; LVEDD $47.0 \pm 4.4$ to $47.1 \pm 4.0 \mathrm{~mm}, p=0.93$ ), whereas in the placebo group, LVEF declined (57.5 \pm $5.6 \%$ vs $63.8 \pm 3.9 \%, p=0.01)$ and both LVESD and LVEDD increased in the placebo group (LVESD $29.7 \pm$ 3.4 to $33.4 \pm 4.5 \mathrm{~mm}$; LVEDD $47.2 \pm 3.8$ to $52.0 \pm 4.6$ $\mathrm{mm}, p=0.01$ for both). NTproBNP increased in the placebo group ( $144 \pm 66$ to $204 \pm 73 \mathrm{pmol} / \mathrm{l}, p=0.01$ ) but remained static in the nebivolol group $(147 \pm 57$ to 152 $\pm 69 \mathrm{pmol} / \mathrm{l}, p=0.77)$ [18]. Thus, nebivolol has a protective role against acute and potentially early cardiotoxicity in cancer survivors who received anthracyclines.

\section{$A R B$ vs beta-blockers}

In the PRADA trial, 130 patients who were recruited with early breast cancer (mean age $50 \pm 10.2$ years) were scheduled to receive epirubicin $[19,26]$. It was a $2 \times 2$ factorial, single-centre, randomized, placebo-controlled, double-blind trial. The primary endpoint was to assess for any change in LVEF from baseline by cardiac MR. A 5\% change was considered clinically important and significant. Participants were randomly assigned to one of the following interventions (1:1:1:1): candesartan cilexetil $32 \mathrm{mg} /$ day and metoprolol succinate $100 \mathrm{mg} /$ day $(n=32)$, candesartan cilexetil $32 \mathrm{mg} /$ day and placebo once per day $(n=33)$, metoprolol succinate $100 \mathrm{mg} /$ day and placebo once per day $(n=32)$, and placebo once per day and placebo once per day $(n=$ 33). Interventions were initiated before the chemotherapy, and dose up-titration was considered every 3 days. The starting dose for candesartan was $8 \mathrm{mg}$ and a maximum of $32 \mathrm{mg}$ per day; for metoprolol, it was $50 \mathrm{mg}$ and a maximum of $100 \mathrm{mg}$ per day. Both TnI and BNP were measured at baseline and after chemotherapy.

After 10-61 weeks of follow-up, changes in LVEF in different groups compared with placebo-placebo arm $[-2.8(95 \%$ CI $-4.3,-1.3)]$ showed that reduction in LVEF was significantly less in the candesartan-placebo arm compared with the placebo-placebo arm [- 0.9 (95\% CI $-2.3,0.4) ; p=0.025]$. There was a less significant reduction in the candesartan-metoprolol arm than in the placebo-placebo arm [- 0.6 (95\% CI - 2.1, 0.8); $p=0.075]$. Moreover, there was no significant difference noted between the metoprolol-placebo arm and placebo-placebo arm [- 2.5 (95\% CI - 3.9, - 1.1); $p=0.71][19,26]$. Interestingly, BNP increased in metoprolol arms but not in the candesartan arms in the absence of development of symptomatic LV dysfunction; this is likely due to its relatively high intra- and inter-individual variability [27]. These findings suggest that attenuation of myocardial injury may not be reflected on the changes in LV systolic function.

\section{The role of $A R B$}

The role of telmisartan was assessed in an RCT of 49 participants [20]. One week before the chemotherapy, 25 were randomized to receive $40 \mathrm{mg} /$ day of telmisartan and 24 received placebo. Echocardiogram, as well as serum samples, including reactive oxygen species and IL-6, was checked before and 7 days after every new dose of epirubicin $\left(100 \mathrm{mg} / \mathrm{m}^{2}\right)$. LV strain and strain rate were assess using standard echo techniques [20]. Interestingly, impairment in the strain rate reached its peak with a cumulative dose of $200 \mathrm{mg} / \mathrm{m}^{2}$ without any differences between the two arms of the study, the intervention and placebo $(1.41 \pm 0.31$ vs $1.59 \pm 0.36 / \mathrm{s})$. With increasing cumulative dose, strain rate normalized only on the intervention arm at the dose of $300 \mathrm{mg} / \mathrm{m}^{2}$ and $400 \mathrm{mg} / \mathrm{m}^{2}(1.69 \pm 0.0 .42$ vs $1.34 \pm 0.18 / \mathrm{s} ; p<0.001$ and $1.74 \pm 0.27$ vs $1.38 \pm 0.24 / \mathrm{s}, p<0.001)$ respectively. A significant increase in reactive oxygen species and IL-6 was observed in the placebo arm without any significant change on the telmisartan arm [20]. These findings indicate that ARB has an effective role in antagonizing the inflammatory effects of chemotherapy as well as its potential effect on reversing early myocardial impairment.

\section{The role of MRA}

Akpek and colleagues enrolled 83 female patients with breast cancer and underwent anthracycline therapy [21]. It was a prospective, randomized, double-blind, and placebo-controlled study. Participants were randomized to spironolactone $25 \mathrm{mg}$ OD $(n=43$, mean age $50 \pm 11$ years) and placebo group ( $n=40$, mean age $51 \pm 10$ years). A fixed-dose of spironolactone was given, and medications were started 1 week before starting chemotherapy. The total period of spironolactone treatment was $24.0 \pm 2.9$ weeks and $24.3 \pm 2.9$ on the placebo arm $(p=0.642)$. $2 \mathrm{D}$ echocardiogram was performed at baseline and repeated 3 weeks after the last chemotherapy cycle to assess LVEF, LVEDD, LVESD, and LV diastolic function. Additionally, TnI and NTproBNP were checked in both groups. There was a significant decline in LVEF in the control group compared with the spironolactone group $(67.7 \pm 6.3$ to $53.6 \pm 6.8 ; p<0.001$ vs $67.7 \pm 6.1$ to $65.7 \pm 7.4 ; p=0.094$ ). Besides, participants on the spironolactone arm had preserved LV diastolic parameters $(p=0.096)$, whereas significantly deteriorated in the control group $(p<0.001)$. 
The TnI level was significantly higher in the control group compared with the intervention group $(p=0.006)$. Serum NTproBNP level increased in both groups without significant differences between the two groups [71 (48-125 pg/ $\mathrm{ml})$ to $85(51-100 \mathrm{pg} / \mathrm{ml}) ; p=0.549$ vs $70(56-72 \mathrm{pg} / \mathrm{ml})$ to $100(89-138 \mathrm{pg} / \mathrm{ml}) ; p=0.089$ ] [21]. In summary, spironolactone is an effective medication in the primary prevention of acute- and early-onset AIC. It provided potential protection for LV systolic and diastolic function as well as myocardial injury.

\section{Discussion}

The data from our research suggested that neurohormonal blockers reduced the reduction in the LVEF and myocardial injury in 14/15 RCTs. The primary endpoint was set almost similar in all the studied RCTs; however, there were slight differences in the target decline in LVEF, almost all of the trials, the target was $\geq 10 \%$ unit decline from baseline LVEF and the baseline LVEF should be $>50 \%$ apart from two trials: MANTICORE 101-BREAST and Gupta et al. (2018) which was $>5 \%$ and $>20 \%$ decline from baseline, respectively. Total participants $(N)$ from all RCTs were 1849; they had either haematological or non-haematological malignancies. All of the participants received anthracyclines, apart from a small number of patients $(n=74)$ who received trastuzumab only in the MANTICORE 101-BREAST study. The rest of the participants from this study $(n=25)$ received both anthracycline and trastuzumab, and the results were similar in each group and parallel to the other trials suggesting a benefit from both b-blockers and ACEI.

The sample size was generally small in all the trials. Besides, most of the RCTs carefully selected their participants with minimal cardiovascular risk and comorbidities, and they were at their middle age. Despite that, the neurohormonal blockers' safety and efficacy were shown suggesting that they might be even more effective in those who have underlying comorbidities like hypertension, coronary artery disease, diabetes mellitus, and chronic kidney disease.

Most of the patients involved in these studies were of middle age rather than elderly patients who are more liable to develop cancer. This can be considered as a limitation for these trials.

Almost all the participants tolerated well these medications, with no issues of poor adherence. Interestingly, the use of different doses of carvedilol was safe and effective in reducing cardiotoxicity. Furthermore, a combination of two drugs like carvedilol and enalapril was observed to be an effective measure to minimize cardiotoxicity.

The imaging modality used in almost all the RCTs was the 2D echocardiogram. Cardiac MRI is more sensitive and accurate in the assessment of LV function. However, due to its availability and cost-effectiveness, the authors' opinion is to use echocardiogram as the first-line imaging modality. In those with poor echocardiographic window, a contrast echocardiogram can be used to enhance LV endocardial borders and accurate measurements of LVEF using Simpson's biplane method. If still difficult, cardiac MRI could be considered if available, no contraindications like claustrophobia, or significant renal impairment due to risk of gadolinium-induced nephrotoxicity. The role of the neurohormonal blockers in preventing LV diastolic function is still controversial, especially the B-blocker, and further research with a large sample size is recommended.

Furthermore, all the trials focused on preventing acute and early cardiotoxicity. Follow-up for all RCTs was 1156 weeks (mode 26 weeks). Evidence is less available about the prevention of late-onset cardiotoxicity, i.e. > 1 year after chemotherapy.

\section{Conclusions}

There are now several small trials with positive outcomes on the use of neurohormonal blockers in primary prevention of anthracycline-induced cardiotoxicity. Based on the currently available evidence, it is prudent to consider those patients, especially with high-risk $\mathrm{CV}$ factors for B-blockers, ACEI, or a combination of both. If intolerant to these medications, other options such as ARB and MRA could be considered. These measures may potentially reduce the risk of acute and early onset cardiotoxicity. Further research is required to study the effects of the medications in patients with anthracyclineinduced acute-, early-, and late-onset cardiotoxicity.

\section{Abbreviations}

2D: Two dimensional; ACEl: Angiotensin-converting enzyme inhibitor; AIC: Anthracycline-induced cardiotoxicity; ARB: Angiotensin receptor blocker; ASCO: American Society of Clinical Oncology; B-blocker: Beta-blocker; BD: Twice a day; BNP: Brain-type natriuretic peptide; CK: Creatine kinase; Cardiac MRI: Cardiac magnetic resonance imaging; ESC: European Society of Cardiology; HF: Heart failure; IL-6: Interleukin-6; LV: Left ventricle; LVEDD: Left ventricular end-diastolic diameter; LVEDV: Left ventricular end-diastolic volume; LVEF: Left ventricular ejection fraction; LVESD: Left ventricular endsystolic diameter; LVESV: Left ventricular end-systolic volume;

MRA: Mineralocorticoid receptor antagonist; RAAS: Renin-angiotensinaldosterone system; RCT: Randomized controlled trial; Tnl: Troponin I

\section{Acknowledgements}

Not applicable

\section{Authors' contributions}

All authors have read and approved the manuscript. AA-conception and design, drafting the chapter, literature research, and drawing conclusions; $\mathrm{NA}$ - conception and design and revising the chapter critically for important intellectual content.

\section{Funding}

This work was not supported by any fund.

Availability of data and materials Not applicable 


\section{Ethics approval and consent to participate}

Not applicable, it is a review article; no ethical commit approval is required.

\section{Consent for publication}

Not applicable

\section{Competing interests}

The authors declare that they have no competing interests.

Received: 3 August 2020 Accepted: 27 August 2020

Published online: 11 September 2020

\section{References}

1. Nabhan C, Byrtek M, Rai A et al (2015) Disease characteristics, treatment patterns, prognosis, outcomes and lymphoma-related mortality in elderly follicular lymphoma in the United States. Br J Haematol 170:85-95

2. Chihara D, Westin JR, Oki Y et al (2016) Management strategies and outcomes for very elderly patients with diffuse large B-cell lymphoma. Cancer

3. Adams MJ, Lipshultz SE (2005) Pathophysiology of anthracycline- and radiation- associated cardiomyopathies: implications for screening and prevention. Pediatr Blood Cancer 44:600-606

4. Grenier MA, Lipshultz SE (1998) Epidemiology of anthracycline cardiotoxicity in children and adults. Semin Oncol 25:72-85

5. Armenian SH, Lacchetti C, Barac A et al (2017) Prevention and monitoring of cardiac dysfunction in survivors of adults cancers: American Society of Clinical Oncology Clinical Practice Guideline. J Clin Oncol 35:893-911

6. Zamorano JL, Lancellotti P, Rodriguez-Munoz D et al (2016) 2016 ESC position paper on cancer treatments and cardiovascular toxicity developed under the auspices of the ESC Committee for Practice Guidelines: The Task Force for cancer treatments and cardiovascular toxicity of the European Society of Cardiology (ESC). Eur Heart J 37:2768-2801

7. Cardinale D, Sandri MT, Colombo A et al (2004) Prognostic value of troponin I in cardiac risk stratification of cancer patients undergoing highdose chemotherapy. Circulation 109:2759-2754

8. Bosch X, Rovira M, Sitges M et al (2013) Enalapril and carvedilol for preventing chemotherapy-induced left ventricular systolic dysfunction in patients with malignant hemopathies: the OVERCOME trial (prevention of left ventricular dysfunction with enalapril and carvedilol in patients submitted to intensive chemotherapy for the treatment of malignant hemopathies). J Am Coll Cardiol 61:1355-2362

9. Pituskin E, Mackey JR, Koshman S et al (2017) Multidisciplinary approach to novel therapies in cardio-oncology research (MANTICORE 101- Breast): a randomized trial for the prevention of trastuzumab-associated cardiotoxicity. J Clin Oncol 35:870-877

10. Gupta V, Kumar Singh S, Agrawal V et al (2018) Role of ACE inhibitors in anthracycline-induced cardiotoxicity: a randomized, double-blind, placebocontrolled trial. Paediatric Blood Cancer 65:e27308

11. Guglin M, Krischer J, Tamura R et al (2019) Randomized trial of lisinopril versus carvedilol to prevent trastuzumab cardiotoxicity in patients with breast cancer. J Am Coll Cardiol 73:2859-2868

12. Georgakopoulos P, Roussou P, Matsakas E et al (2010) Cardioprotective effect of metoprolol and enalapril in doxorubicin-treated lymphoma patients: a prospective, parallel-group, randomized, controlled study with 36-month follow-up. Am J Haematol 85:894-896

13. Maryam N, Ghasem J, Saideh B et al (2017) Cardioprotective effects of carvedilol in inhibiting doxorubicin-induced cardiotoxicity. J Cardiovasc Pharmacol 69:279-285

14. Tashakori Beheshti A, Mostafavi Toroghi H, Hosseini G et al (2016) Carvedilol administration can prevent doxorubicin-induced cardiotoxicity: a doubleblind, randomized trial. Cardiology 134:47-53

15. Kalay N, Basar E, Ozdogru I et al (2006) Protective effects of carvedilol against anthracycline-induced cardiomyopathy. J Am Coll Cardiol 48

16. Abuosa AM, Elsheikh A, Kinsara A et al (2018) Prophylactic use of carvedilol to prevent ventricular dysfunction in patients with cancer treated with doxorubicin. Eur Heart J 39:6255

17. Avila MS, Ayub-Ferreira SM, Wanderley MRB Jr et al (2018) Carvedilol for the prevention of chemotherapy-related cardiotoxicity: the CECCY trial. J Am Coll Cardiol 71:2281-2290

18. Kaya MG, Ozkan M, Gunebakmaz O et al (2013) Protective effects of nebivolol against anthracycline-induced cardiomyopathy: a randomized control study. Int J Cardiol 167:2306-2310
19. Gulati G, Heck S L, Ree A H et al (2016) Prevention of cardiac dysfunction during adjuvant breast cancer therapy (PRADA): a $2 \times 2$ factorial, randomized, placebo-controlled, double-blind clinical trial of candesartan and metoprolol Eur Heart J 37:1671-1680

20. Cadeddu C, Piras A, Mantovani G et al (2010) Protective effect of the angiotensin II receptor blocker telmisartan on epirubicin-induced inflammation, oxidative stress, and early ventricular impairment. Am Heart J 160:487

21. Akpek M, Ozdogru I, Sahin O et al (2014) Protective effects of spironolactone against anthracycline-induced cardiomyopathy. Eur J Heart Fail 17:81-89

22. Okumura $\mathrm{K}$, Jin $\mathrm{D}$, Takai $\mathrm{S}$ et al (2002) Beneficial effects of angiotensinconverting enzyme inhibition in adriamycin-induced cardiomyopathy in hamsters'. Jpn J Pharmacol 88:183-188

23. Tokudome T, Mizushigr K, Norma T et al (2000) Prevention of doxorubicin (adriamycin)-induced cardiomyopathy by simultaneous administration of angiotensin-converting enzyme inhibitor assessed by acoustic densitometry. J Cardiovasc Pharmacol 36:361-368

24. Cardinale D, Colombo A, Sandri MT et al (2006) Prevention of high-dose chemotherapy-induced cardiotoxicity in high-risk patients by angiotensinconverting enzyme inhibition. Circulation 114:2474-2481

25. Cardinale D, Sandri MT, Martinoni A et al (2000) Left ventricular dysfunction predicted by early troponin I release after high-dose chemotherapy. J Am Coll Cardiol 36:517-522

26. Gulati G, Heck SL, Rosjo H et al (2017) Neurohormonal blockade and circulating cardiovascular biomarkers during anthracycline therapy in breast cancer patients: results from the PRADA (Prevention of Cardiac dysfunction during adjuvant Breast Cancer Therapy) study. J Am Heart Assoc 6:e006513

27. Wu AHB (2006) Serial testing of B-type natriuretic peptide and NTpro-BNP for monitoring therapy of heart failure: the role of biologic variation in the interpretation of results. Am Heart J 152:828-834

\section{Publisher's Note}

Springer Nature remains neutral with regard to jurisdictional claims in published maps and institutional affiliations.

\section{Submit your manuscript to a SpringerOpen ${ }^{\circ}$ journal and benefit from:}

- Convenient online submission

- Rigorous peer review

- Open access: articles freely available online

- High visibility within the field

- Retaining the copyright to your article

Submit your next manuscript at $\boldsymbol{\nabla}$ springeropen.com 